\title{
Mobile Application for Uploading Marks and Student Attendance Management System
}

\author{
Vamshi Krishna A, Kirupa Ganapathy
}

\begin{abstract}
Student presence in the classroom could be a very important issue so as to monitor student's performance within the class compared to their studies. It turns into the main reason that the college management keeps up a standard that a student can just go to in the test if his/her participation is higher or equivalent to a few rates (70\% to $80 \%)$. In the traditional attendance system, this can be the waste of time to note and marking every student's name in the attendance register. Hard copy of the marked register might get lost even. By using the latest updated android technology, a teacher can take attendance easily and can provide student's semester marks and student can able to see it with their unique Id. Using this technology, marked attendance will be saved in the phone yet as in server also and it checks and can be shared. With the stored information, can perform attendance percentage calculations and can remind by sending SMS to their guardian to stay them refresh regarding their kid's attendance in the Institute. Technology's in this application are Angular-6, ExpressJs, NodeJs and MongoDb.
\end{abstract}

Keywords: Attendance, proxy, college management, Angular6, ExpressJs, NodeJs and MongoDb

\section{INTRODUCTION}

Nowadays, student's attendance administration is a severe problem in educational organizations. Presently student's attendance in the classroom is recording by marking in their attendance register when the faculty is taking class. If it's hard to pass the sheet over the students then the faculty may take the complete consideration from students for marking in the register.

Primary focal point of the paper is to show the use of android phone in the area of attendance management system. These days Android phone is common to every one so, a faculty can undoubtedly mark attendance and process it where it needs. Principal advantages of the application are that the instructor can get computerized percentage, can able to take the print of the saved data which guarantees that data will never lose and can utilize it where needed. The instructor takes attendance in the phone and application make to process the data which is marked by the faculty and also the data would be saved in the web server. An online database would be used or any backend database for storing the marked attendance. System developed successfully followed by the client-server framework. Firstly, the design of the system was taken next by the complete

Revised Manuscript Received on August 14, 2019.

Vamshi Krishna A, Department of Electronics and Communications Engineering, Saveetha School of Engineering, Saveetha Institute of Medical and Technical Sciences, Chennai, Tamilnadu, India(email: krishna6534159@gmail.com)

Dr. Kirupa Ganapathy, Professor, Department of ECE, Saveetha School of Engineering, SIMATS,Chennai, Tamilnadu, India (email: kirupa1980@gmail.com) implementation of the system both on server side and from the Android side. The total development was finalized only after all the overall system testing.

\section{METHODOLOGY AND STRUCTURAL DESIGN}

For registration of student's, an application is being developed by putting together the both android device and web service.

In this paper, the main methodology which needs to proceed for this application is in the following steps:

1. Front-End

2. Back-End

3. Database

4. Mobile application

1. Front-End: In frontend, the latest technologies used are,

$\begin{array}{ll}\circ & \text { Angular } \\ \circ & \text { HTML } \\ \circ & \text { CSS }\end{array}$

Angular:

Angular is the technology which is performing a main role in the frontend. Here, it is used for designing the UI interaction and to build the total application by creating the separate component wise and creating modules. Data from the backend is retrieved by creating a service component in an angular

Html:

As HTML is not required, this technology is just used for simple template actions in the angular component as component.html

CSS:

This technology is used to give users a good look of an application separately from its construction as to give color to the Frontend part.

\section{Back-end: \\ ○ Express.js \\ ○ Node.js}

Express.js:

It is a framework which is used in the backend and can be runnable in the Node.js platform and this technology can connect the database to the frontend through this technology. Through an API connection, it will connect the frontend with the backend. 
Some features used in this application:

- It's an API connection between the frontend and the backend, which responds to HTTP Requests.

- Can perform many actions based upon HTTP method's and URL's.

- Depends upon the arguments passed rendering of the HTML pages' render dynamically.

Node.js:

This technology is used as a platform to run the express application on it. And it is used to connect the database through it.

\section{Database:}

Here the database utilized is the MySQL. It is a table sort where the entire information will be in this organization. We use embed questions here and recover the information and will be taken at the front-end of the application. This database is connected to the frontend through an API connection which is built with Express.Js and Node.Js

\section{Mobile application:}

Built up a login page utilizing a versatile application and associated it to the site application. So that once the student login then it will divert to the site.

By putting up together all the above components process the application that can be managed by the faculty for the student attendance and for uploading student's marks. More than uploading marks and attendance, this application is capable of retrieving faculty handling courses, student's database from the main server and stores in the mobile internally. Express.js API acts as the interface in between the application and the backend database which is MySQL. Handling of their accounts and courses can be handled by browsing through online and even for students also to check their data. Backend MySQL contains whole student's and faculty's data also.

\section{RESULTS}

\section{Proposed Idea: -}

Proposed solution for student's attendance management is to done by building a system that is:

- $\quad$ Less cost efficient and good portability

- Gets connected with the organization main server and to its database

- $\quad$ Speed of accessing for both students and faculty should be good

Only thing for meeting the above criteria is to implement an android application which can be accessible by the website even when needed. Now-a-days, usage of android mobiles is increasing widely and becoming popular. As we are dealing with many applications daily, it won't take much time for understanding this application. Mostly it will be downloaded from the play store.

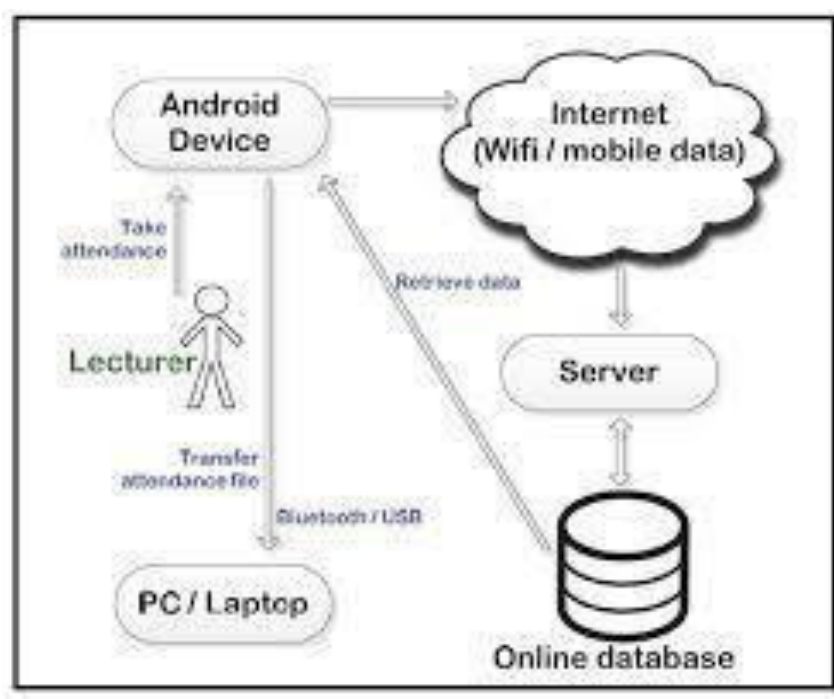

Fig 1: - Designed application for attendance system

\section{Flow of the Application:}

Application starts by displaying the college picture as a background image and then displays the registration or login screen. Registration screen displays to select the role type either the faculty or the student.

During the class, faculty login into the application and choose the current handling course with in the class. Then whole class list throughout the semester will get displayed from the main server.

Then the faculty marks over the attendance by calling. Once the instructor marked, once giving the done button then the screen conjointly shows the total absentees and once confirmed, instructor submits the attendance of that class. After marking, a process involves that where the marking will get recorded, and sending the attendance update back to the central database. Now, students can be able to check their attendance by opening and logging into the student's login page. The data get retrieve from the local server once the instructor submits the attendance.

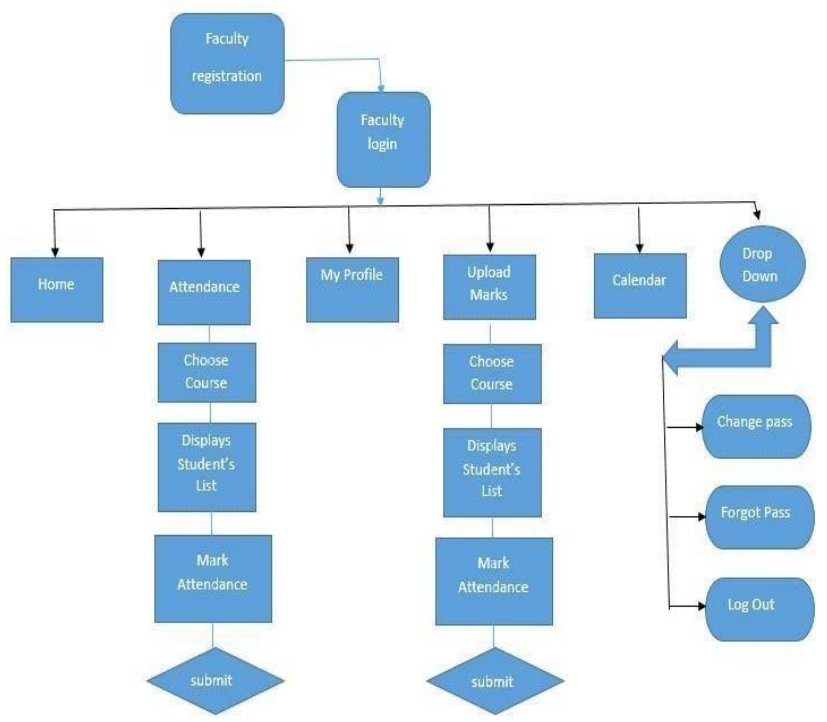

Fig.2. Main screen and the front-end view of the faculty login Screening: - 
Application is built of multiple screens apart from the main screen. When faculty login is successful then the screen displaying as shown in below

- Home

- My profile

- Student's data

- $\quad$ My Subjects

- $\quad$ Attendance

- Upload Marks

Courses gets retrieved from the database by linking with the faculty web service and will be saved internally. Faculty can choose one of the above given options from their main screen. Faculty main screen contains a dropdown containing 3 buttons like,

- $\quad$ Profile

- $\quad$ Change password

- Logout

By selecting Attendance or Upload marks, data will get updated automatically to the database. This is to be done by linking it with faculty web service. The retrieved data related to attendance, marks can be viewed by the students by retrieving from the server. The main screen once the student login, it displays a list of options like,

- $\quad$ My profile

- $\quad$ Faculty's lis

- $\quad$ My Courses

- Attendance

- Home

- Calendar

As similar to the faculty's side, for the student also the above list of options will get within the application of the student main screen as shown in the fig. 3 . When the student visits attendance or marks or faculty list, data relates to the student will gets retrieved from the database by connecting to the student web service.

A dropdown button is given which is of containing 3 buttons like,

- $\quad$ Forgot Password

- Change password

- $\quad$ Log Out

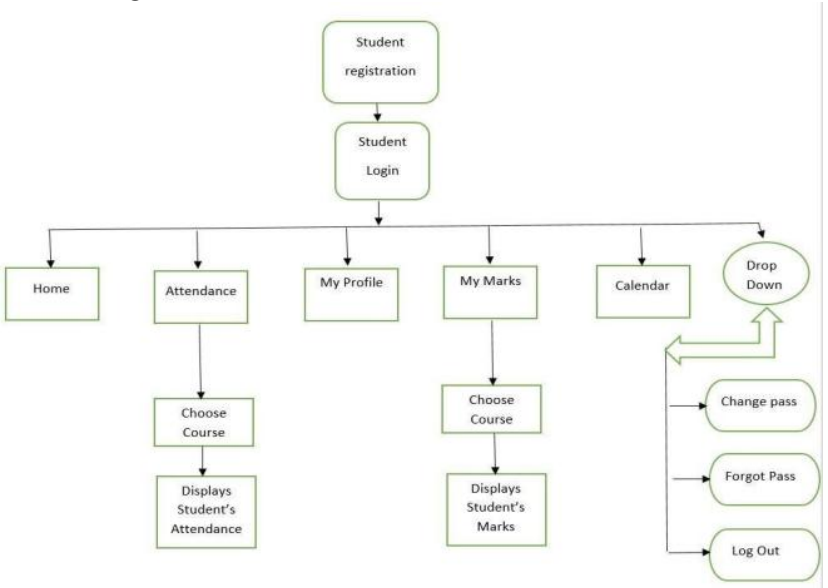

Fig.3. Main screen and the front-end view once the Student login
- Marks

\begin{tabular}{|l|l|l|l|l|}
\hline S. No. & Subject code & Registration Number & $\begin{array}{l}\text { Name of the } \\
\text { Student }\end{array}$ & $\begin{array}{l}\text { Attendance } \\
\text { Marking }\end{array}$ \\
\hline & & & & \\
\hline & & & & \\
\hline
\end{tabular}

Fig.1. Displaying of marking attendance to students

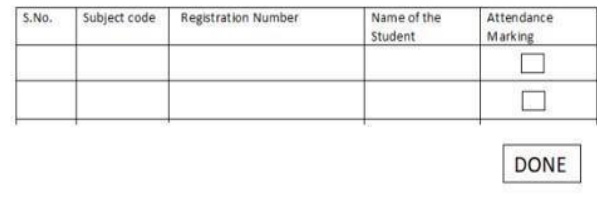

Fig.1.1. Displaying absentees list before uploading attendance

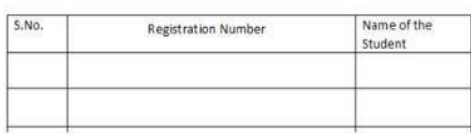

SUBMIT

Fig.1.2. Displaying to submit attendance after confirming absentees

The above-shown diagram gives information about, how the instructor marks the attendance to students.

Fig. 1 is the main screen of giving attendance

Fig. 1.1 displays the screen while marking attendance.

Fig.1.2 displays the absentees list once given the DONE button and get updated once gives SUBMIT button.

\begin{tabular}{|l|l|l|l|l|l|l|l|}
\hline S. No. & $\begin{array}{c}\text { Subject } \\
\text { code }\end{array}$ & $\begin{array}{c}\text { Registration } \\
\text { Number }\end{array}$ & $\begin{array}{c}\text { Name of } \\
\text { the } \\
\text { Student }\end{array}$ & CIA -1 & CIA -2 & Model & Semester \\
\hline & & & & & & & \\
\hline & & & & & & & \\
\hline
\end{tabular}

\section{Displaying of Allotting marks to students}

Above table gives the display of the page how the faculty allot marks to the students. Instructor gets the total students data once selects the particular course and enter marks by student wise.

\begin{tabular}{|l|l|l|l|l|}
\hline S. No. & Subject code & Registration Number & Name & Present/absent \\
\hline & & & & \\
\hline & & & & \\
\hline
\end{tabular}

Fig. a. Display to check the student attendance marked / not
\begin{tabular}{|l|c|c|c|l|l|l|l|}
\hline S. No. & $\begin{array}{c}\text { Subject } \\
\text { code/ } \\
\text { Name }\end{array}$ & $\begin{array}{c}\text { Registration } \\
\text { Number }\end{array}$ & $\begin{array}{c}\text { Name of } \\
\text { the } \\
\text { Student }\end{array}$ & CIA -1 & CIA -2 & Model & Semester \\
\hline & & & & & & & \\
\hline & & & & & & & \\
\hline
\end{tabular}

Fig. b. Display for student to check marks

Fig. a. is the page displaying when student checking out their attendance.

Fig. b. is the page display for the student once he login into student role type.

Published By 


\section{MOBILE APPLICATION FOR UPLOADING MARKS AND STUDENT ATTENDANCE MANAGEMENT SYSTEM}

\section{Literature Survey: -}

[1]. Zhang et al. given a track of attendance, which is an alternative view of attendance.

[2]. B. N. Gatsheni, R. B. Kuriakose, and F. Aghdasi developed attendance taking by using RF identification technology with internet hotspot. Using student ID card the attendance will be taken when the student entered the classroom

[3]. Z. Zhan, P. Gong, L. Cao and Y. Chen, built an application with visual studio as IDE, .NET also used which gives a overlook of attendance administration with current organization framework, looking over just on recording attendance, Oracle. Mohamed et al.

[4] B. K. P. Mohamed and C. V. Raghu, proposes outlined gadget by a unique finger impression that is utilized as a part of a unique finger impression attendance framework. By placing the student thumb on the gadget sensor attendance gets marked. We have lack of one feature here is that scanner may not always detect for the first time. Using framework application real time examples like, mobile ticketing, monitoring attendance in schools, home utilities, security, glucose meter, and so forth [5] M. Strommer et al.

[6]. In RFID Sens Net Lab, a robotized attendance monitoring application was processed both in electronic and portable side. Cost of system is expensive. Soweto et al.

[7]. B. Soewito, F. L. Gaol, E. Simanjuntak, and F. E. Gunawan, implemented an attendance management system by taking fingerprint impression and GPS technology through an android device. This system involves fingerprint sensor completely so it is more time consuming. This system can able to retrieve data but the .pdf or.xlsx files could not be generated.

Noor et al.

[8]. S. A. M. Noor, N. Zaini, M. F. A. Latip and N. Hamzah, proposed an automation attendance monitoring system. Here in this system, ID card will be giving to every student which has a unique barcode which is taken by the android application. Main drawback here is the other student's ID card may carry by the single person which mislead the attendance system.

\section{Results and Output: -}

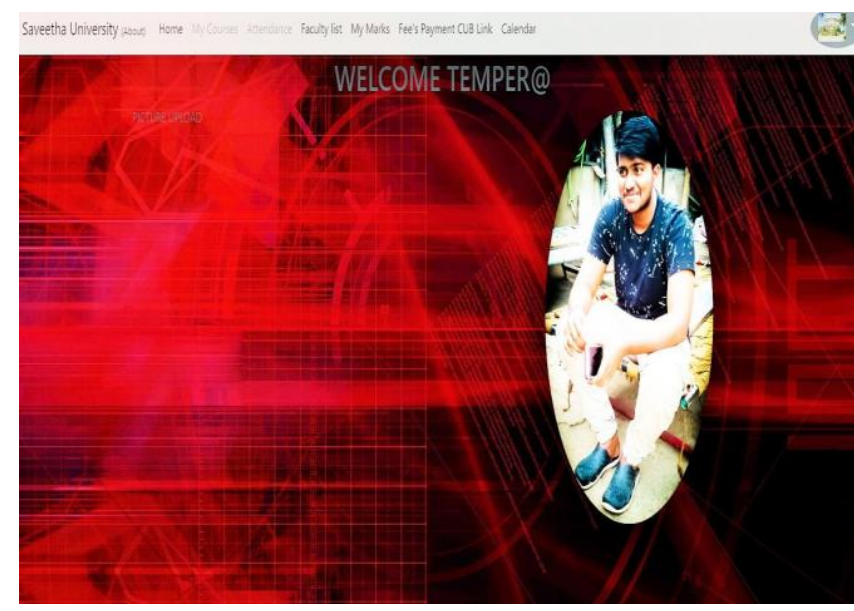

Fig.4. Display of the main screen of the Faculty

The above figure is the display once the faculty logged in. It displays a message with the name of the user. On top of the screen, it is displaying like Home, My Subjects, etc., all are the links which redirects to the respective web pages.

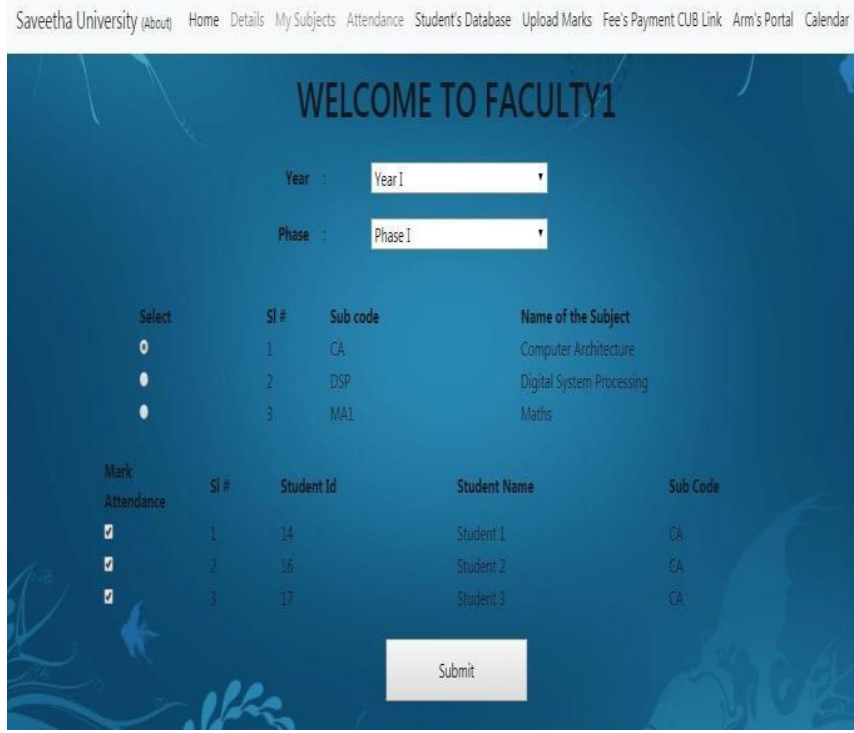

Fig.5. Display of Page when Faculty giving Attendance

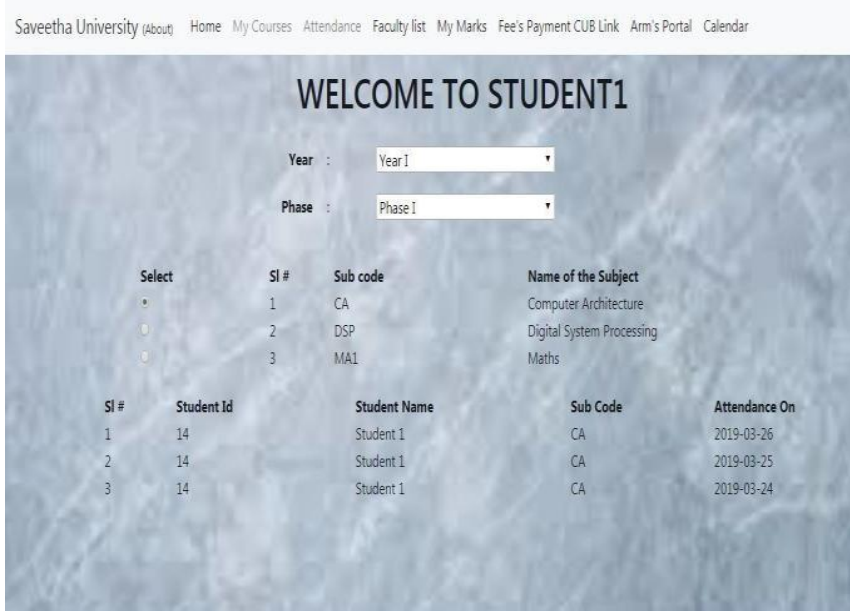

Fig.6. Display of Attendance view once the Student Login

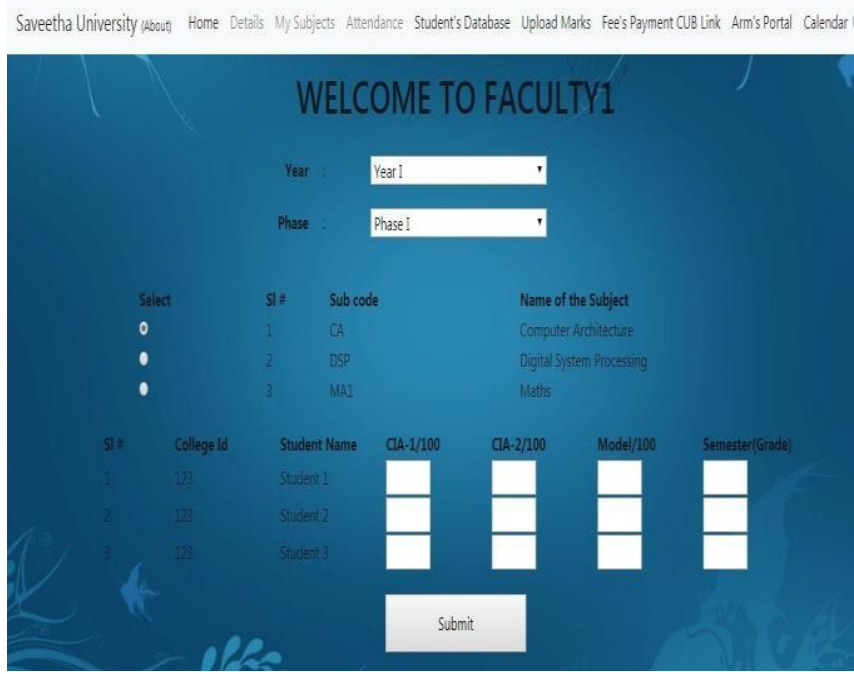

Fig.7. Display of Page when Faculty uploading Marks

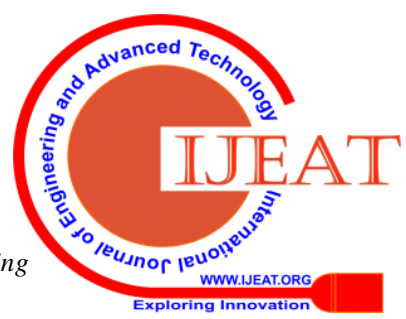


Saveetha University (about) Home My Cousses Attendance Fracty)/ist MyMarks Fee's Pajment CuB Link Amms Portal Calendar

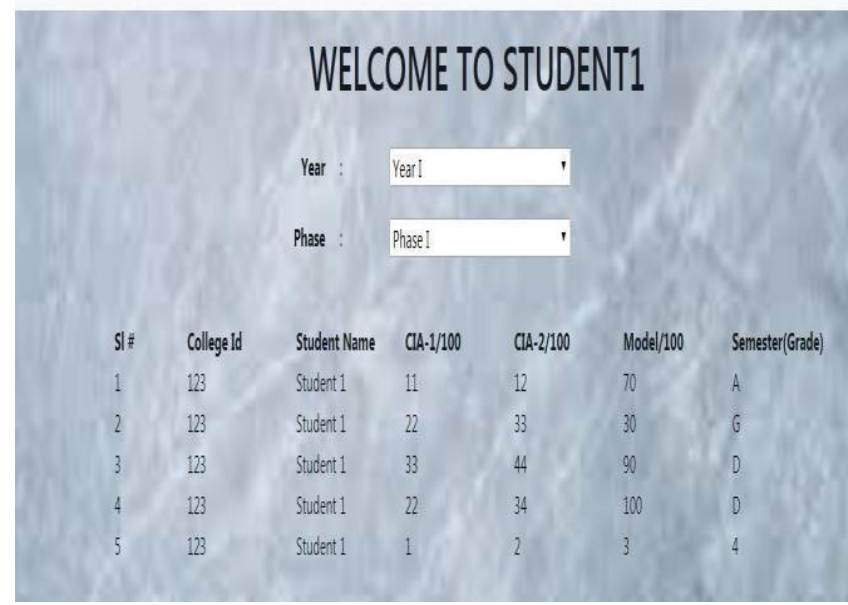

Fig.8. Display of Marks view once the Student's Login

Executed this application by taking 40 users data and separated $20-20$ by selecting role type as student and faculty. Once student login, marks, and attendance displayed by retrieving from the database as shown in fig. a and fig. $b$ and in fig.c. it is shown how data is getting from the server when the faculty upload marks or attendance and from fig. 2 and fig. 3 it is shown, how the display of the frontend view of the faculty and the student.

\section{CONCLUSION}

Attendance monitoring mobile application can considerably improve the traditional way of attendance marking in most of the surrounding universities. Attendance monitoring mobile application is of automatic calculation by the system, that results in a lot of precise information entry. This keep student attending information area unit framed and investigate surely without losing of data, compared to a conventional monitoring technique. Course handling faculty will simply take the student's attendance which can be stored and retrieved easily as a result of the less time needed to gather and method information. By implementing this application in surrounding universities makes easier to spot attending, automatic calculation, etc. A text message sent by the system automatically to remind parents so that they would be intimated regarding their kid's performance and progress within the organization.

\section{REFERENCES}

1. G.P. Zhang, "Research on the management system of University Students," Northeast Normal University, China, pp. 17-19, 2013.

2. B. N. Gatsheni, R. B. Kuriakose and F. Aghdasi, "Automating a student class attendance register using radio frequency identification in South Africa," 2007 IEEE International Conference on Mechatronics, Kumamoto, pp. 1-5, 2007.

3. Z. Zhang, P. Gong, L. Cao and Y. Chen, "Design and Implementation of Educational Administration Attendance Management System Based on B/S and C/S," 2007 First IEEE International Symposium on Information Technologies and Applications in Education, Kunming, pp. 606-609, 2007.

4. B. K. P. Mohamed and C. V. Raghu, "Fingerprint attendance system for classroom needs," 2012 Annual IEEE India Conference (INDICON), Kochi, pp. 433-438, 2012.
5. M. Strommer et al., "Smart NFC Interface Platform and its Applications," in T. Tuikka and M. Isomursu, (Eds.), Touch the Future with a Smart Touch, 2009.

6. RFID Sens Net Lab, "A white paper on Automatic Attendance System," Texas A \& M University, Texas, USA, 2005.

7. B. Soewito, F. L. Gaol, E. Simanjuntak and F. E. Gunawan, "Attendance system on Android smartphone," 2015 International Conference on Control, Electronics, Renewable Energy, and Communications (ICCEREC), Bandung, pp. 208-211, 2015.

8. S. A. M. Noor, N. Zaini, M. F. A. Latip and N. Hamzah, "Android-based attendance management system," 2015 IEEE Conference on Systems, Process and Control (ICSPC), Bandar Sunway, pp. 118-122, 2015.

9. M. Kassim, H. Mazlan, N. Zaini and M. K. Salleh, "Web-based student attendance system using RFID technology," 2012 IEEE Control and System Graduate Research Colloquium, Shah Alam, Selangor, pp. 213218, 2012. 